\title{
A Better Way to Know What Patients Believe and Value about Health
}

\author{
Namratha R. Kandula, MD, MPH \\ Department of Medicine, Northwestern University, Chicago, IL, USA. \\ J Gen Intern Med 29(4):560-1 \\ DOI: $10.1007 / \mathrm{s} 11606-013-2714-8$ \\ (c) Society of General Internal Medicine 2013
}

I $\mathrm{n}$ every medical school, residency training, and professional society, there is a push for doctors to practice "patient-centered" medicine. A central tenet of patientcentered medicine is that the patient's values and beliefs guide the treatment. But what does that really mean? And how are doctors, who face increasing time pressure, supposed to know what a patient believes and values about health?

As a primary care doctor, I have been trained from medical school, and onwards, to take a history from patients that mostly focuses on organs and symptoms. The traditional medical history is based on the false idea that health is largely "physical." However, in a national survey, $30 \%$ of Americans said that health is a mix of emotional, spiritual, mental, and social factors. ${ }^{1}$ This matters because what patients believe about health has been linked to their willingness to change health behaviors, take medications, and even whether or not the patient's health improves. ${ }^{2}$

After many years of patient care and research on patients' explanatory models of health and disease, I have learned that there is a more effective and efficient way for doctors to understand what a patient believes and values about their health.

Here's how. Start the visit with what I call, 'The two questions that every medical student and doctor should be asking their patients.' These two simple questions, developed by health communication experts and used mostly in research settings, ${ }^{1}$ are: "How is your health," followed by, "How do you know (or, why do you think that)?"

"Hmmmm," - the patient often says in response, "No one has ever asked me that," or, "I never really thought about it." But if I give them just a few seconds, they become fountains of valuable information about what's making them sick, what keeps them healthy, and what matters most to them about their health. That's true even for men, who,

Published online November 16, 2013 we know, are less likely than women to see a doctor or to ask questions at the visit.

Let me illustrate. When I asked these questions of Carl, one new patient, he said his health was "just okay." Asked how he knew, Carl said, "Because right now I take high blood pressure medicine. I want to get off the medicine and lose weight. It's hard because I don't like running, though I enjoy walking. My weight has been a struggle ever since I was a kid." For a 47year-old man, that was a veritable flood of insight.

With this information, I could quickly focus on Carl's priorities. I offered information on the Dietary Approaches to Stop Hypertension (DASH) diet and encouraged him to walk for exercise. I acknowledged his lifelong weight struggles with empathy, becoming his ally. Studies show that when doctors and patients develop a treatment plan as allies, patients benefit far more.

The results? Six months later, Carl had lost $11 \mathrm{lb}$, his blood pressure was lower, and we cut down his medication. Two questions had resulted in better care and a healthier patient.

In a recent study, patients reported that patient-centered decision making occurred least often in routine primary care situations, such as being started on blood pressure or lipidlowering medicines. ${ }^{3}$ But these routine situations are exactly when these two questions are most helpful, because the answers provide key information on the patient's values and beliefs - which has to be the starting point for any patient-centered decision making.

Here's another example. Sondra, a 64-year-old woman, answered my first question by saying that her health was "better now, pretty good," because she had, at last, finished cancer treatment. The treatment caused "bad side effects and depression," she explained, "but I also had a lot of family support." Sondra said she knew her health was pretty good because, "my energy is back, and I want to start traveling again." Our visit focused on keeping her energetic and making sure her depression was controlled, so that she could do the things she felt she missed during cancer treatment. And I had learned that I could involve her family in her care, if I needed - another hallmark of quality health care.

Primary care physicians face increasing time pressure and burn-out. These two questions are effective and efficient in helping me crack open the black box of my patients' lives, beliefs, and values - and they bring me closer to patients, instead of keeping them at a distance.

The next time you are with a patient, try asking these two questions. The answers will help you learn what you really 
need to know about your patients and can help fulfill the promise of patient-centered care.

Corresponding Author: Namratha R. Kandula, MD, $M P H$ Department of Medicine, Northwestern University, 750 N. Lakeshore Drive - 10th Floor, Chicago, IL 60611, USA (e-mail: nkandula@nmff.org).

\section{REFERENCES}

1. Makoul G, Clayman ML, Lynch EB, Thompson JA. Four concepts of health in America: results of national surveys. J Health Commun. 2009; 14:3-14.

2. Aboumatar HJ, Cooper LA. Contextualizing patient-centered care to fulfill its promise of better health outcomes: beyond who, what, and why. Ann Intern Med. 2013;158:628-9.

3. Fowler FJ, Gerstein BS, Barry MJ. How patient centered are medical decisions?: results of a national survey. JAMA. 2013;173:1215-21. 